\title{
Protease Inhibitors and their Relation to Protease Activity in Human Milk
}

\author{
TOR LINDBERG ${ }^{(25)}$, KJELL OHLSSON, AND BJÖRN WESTRÖM \\ Departments of Paediatrics and Experimental Research, Malmö General Hospital, University of Lund, and \\ Department of Zoology, University of Lund, Lund, Sweden
}

\begin{abstract}
Summary
Protease inhibitors and protease (caseinolytic, elastinolytic and esterolytic) activity were analysed in 190 milk samples from $\mathbf{9 4}$ mothers from day 1 to day 160 after delivery The main protease inhibitors in human milk are $\alpha_{1}$-antichymotrypsin and $\alpha_{1}$-antitrypsin. As measured by electroimmunoassay, the level of $\alpha_{1}$-antichymotrypsin in day 1 colostrum was higher than that in normal serum. Trace amounts of inter- $\alpha$-trypsin inhibitor, $\alpha_{2}$-antiplasmin, $\alpha_{2}$-macroglobulin, antithrombin III, or antileukoprotease could be demonstrated. According to their protease inhibiting activity, the 53 milk samples from day 1-3 could be divided into two groups. (1) Presence of protease inhibiting activity $(n=35)$. Both $\alpha_{1}$ antitrypsin and $\alpha_{1}$-antichymotrypsin appeared intact and were able to form complexes with added trypsin or chymotrypsin although the major part of $\alpha_{1}$-antichymotrypsin showed a retarded electrophoretic mobility. The proteolytic activity was undetectable or low in these samples. (2) No protease inhibiting activity, in spite of the presence of immunoreactive inhibitors $(n=18)$. $\alpha_{1}$-Antichymotrypsin had a precipitate pattern similar to group 1 , whereas $\alpha_{1-}^{-}$ antitrypsin had a major fraction with slightly retarded mobility and two minor peaks in the $\alpha-_{1}$ and $\beta$-regions. These precipitate patterns were unchanged on addition of human trypsin or chymotrypsin compatible with the presence of nonreactive inhibitor only. These samples had a caseinolytic and esterolytic activity with an electrophoretic mobility in the $\beta$-region.

All samples from day 4 and later had a demonstrable protease inhibiting activity.
\end{abstract}

\section{Speculation}

About two-thirds of colostral milk samples have a protease inhibiting activity, i.e., can inhibit proteolytic enzymes present in or added to human colostrum. One-third has no protease inhibiting activity, and possess free protease activtiy. These different properties of human colostrum may cause differences in the absorption of proteins in newborn infants.

Protease inhibiting activity and protease activity have been demonstrated in human milk $(5,7,11,20)$. The protease inhibitors, $\alpha_{1}$-antitrypsin and $\alpha_{1}$-antichymotrypsin, were determined immunochemically and found to be present in considerably larger amounts in colostrum than in mature milk (11). A disparity was found between the protease inhibiting activity and the amount of these protease inhibitors in colostrum (11). The reason for this disparity is not known, but it indicates the presence of inactive protease inhibitors. We also do not know anything about the physiologic role of the protease inhibitors in human milk. Finally, we have no information whether other protease inhibitors, e.g., inter- $\alpha$-trypsin inhibitor, $\alpha_{2}$-antiplasmin, antithrombin, and antileucoprotease (14) are present in human milk.

This study was performed to elucidate these questions.

\section{MATERIALS AND METHODS}

Human milk. 190 samples from 94 mothers were collected after informed consent by a breast-pump in sterile test tubes from the first day up to day 160 after delivery. Four of the samples were obtained from four mothers of preterm infants born at the gestational ages of $30,31,35$ and $36 \mathrm{wk}$. The milk was centrifuged at $3000 \mathrm{X} \mathrm{g}$ for $15 \mathrm{~min}$, and the fat layer removed. The skimmed milk was recovered and stored at $-20^{\circ} \mathrm{C}$ until analysed.

Antisera. Rabbit antibodies against human $\alpha_{1}$-antitrypsin, $\alpha_{1}$ antichymotrypsin, $\alpha_{2}$-macroglobulin, inter- $\alpha$-trypsin inhibitor, antithrombin III, and antileucoprotease (17) were available in our laboratories. $\alpha_{2}$-Antiplasmin was a gift of D. Collen, Leuven, Belgium. Seronorm Protein (Nyegaard \& Co. A.A., Oslo, Norway) was used as a standard serum.

Chemicals. Agarose (Miles Lab. Ltd., Stoke Poges, England); Casein Hammarsten (BDH); Bovine albumin (Sigma); AcetylDL-phenylalanine $\beta$-naphtylester, APNE, (Sigma); N-carbobenzoxyalanine- $\beta$-naphtyl ester, CBZ-ANE, (Bachem, Bubenborf, Switzerland); Bovine chymotrypsin (Sigma); Porcine trypsin (Novo, Copenhagen, Denmark); porcine elastase (Worthington); human chymotrypsin and cationic trypsin (16) were available in our laboratory.

All other chemicals were of analytical grade.

Immunochemical methods. Crossed immunoelectrophoresis (4), electroimmunoassay (10), and immunodiffusion according to Ouchterlony (19) were performed with 0.075 moles/liter barbitalsodium barbital buffer, pH 8.6 containing 0.002 moles/liter calcium lactate.

Electrophoresis was performed in $1 \%$ agarose gel with 0.075 moles/liter barbitalsodium-barbital buffer $\mathrm{pH} 8.6$ containing 0.002 moles/liter calcium lactate (8).

Protein was measured according to Lowry et al. (12) with bovine albumin as standard.

Proteolytic activity. The protease activity in human milk was estimated by means of radial digestion of casein in agarose gel. A slide with a gel containing $1 \%$ agarose and $0.1 \%$ casein was immersed for $1 \mathrm{~h}$ in 0.1 moles/liter Tris- $\mathrm{HCl} \mathrm{pH} \mathrm{7.8.} \mathrm{The} \mathrm{samples}$ were poured into the wells and incubated at $37^{\circ} \mathrm{C}$ for $24 \mathrm{~h}$. The slide was then washed and eluted for three days in physiologic saline and immersed in $2 \%$ acetic acid for $1 \mathrm{~h}$ and stained with Coomassie Brilliant Blue R-250.

The caseinolytic activity was also studied after electrophoretic separation of human milk. The electrophoretical conditions were as described above except for the use of a $1 \%$ agarose gel to which $0.1 \%$ casein was added. After the electrophoresis the gel was incubated, washed, and stained as described above.

Elastinolytic activity in human milk was assayed with radial digestion of elastin in agarose gel (15).

Esterolytic activity of human milk against the chromogenic substrates APNE and CBZ-ANE was detected after agarose gel electrophoresis by immersing the gels in a solution of the substrates for $1 \mathrm{~h}$ at $37^{\circ} \mathrm{C}$. The incubation solution consisted of $25 \mathrm{mg}$ APNE dissolved in $10 \mathrm{ml}$ dimethylforamid or $25 \mathrm{mg} \mathrm{CBZ}$-ANE dissolved 
in $25 \mathrm{ml}$ dimethylformamid, $100 \mathrm{mg}$ Fast Blue B salt (Sigma) and 0.1 moles/liter Tris- $\mathrm{HCl}$ buffer, $\mathrm{pH} 7.8$, up to $\mathrm{I00} \mathrm{ml}$. After incubation the gels were fixed in $2 \%$ acetic acid (23).

Demonstration of protease inhibiting activity. Localization of trypsin and chymotrypsin inhibiting activities on electrophoretically separated human milk in agarose gels were carried out using APNE as substrate (24). The gels were incubated for $30 \mathrm{~min}$ in a $0.01 \mathrm{mg} / \mathrm{ml}$ solution of porcine trypsin or bovine chymotrypsin in 0.1 moles/liter Tris-HCl buffer, $\mathrm{pH} \mathrm{7.8.} \mathrm{The} \mathrm{gels} \mathrm{were} \mathrm{then}$ immersed in the APNE-solution as described above. Localization of elastase inhibiting activity was demonstrated accordingly with porcine elastase and with the substrate CBZ-ANE.

Chymotrypsin-binding capacity of $\alpha_{1}$-antichymotrypsin and the trypsin-chymotrypsin-binding capacity of $\alpha_{1}$-antitrypsin were tested using crossed immunoelectrophoresis with the respective antisera. Reaction mixtures of $100 \mu \mathrm{lmilk}$ and increasing amounts of human cationic trypsin or chymotrypsin in 0.1 moles/liter Tris$\mathrm{HCl}$ buffer, $\mathrm{pH} 7.4$, containing 0.15 moles/liter $\mathrm{NaCl}$, were incubated at room temperature $30 \mathrm{~min}$ before electrophoretic separation.

Gel filtration was performed on Ultrogel ACA-44 utilizing a column $2.5 \times 100 \mathrm{~cm}$ equilibrated with 0.05 moles $/$ liter Tris- $\mathrm{HCl}$ buffer, containing 0.5 moles/liter $\mathrm{NaCl}, \mathrm{pH}$ 7.4. The column was calibrated with the following molecular weight markers: soybean trypsin inhibitor, chymotrypsinogen, bovine serum albumin, catalase, and ferritin (Kemila AB, Stockholm, Sweden). The elution of $\alpha_{1}$-antitrypsin and $\alpha_{1}$-antichymotrypsin was followed in the fractions from the column utilizing electroimmunoassay.

\section{RESULTS}

Presence of protease inhibitors. With the immunochemical methods used, only the absence or trace amounts of inter- $\alpha$-trypsin inhibitor, $\alpha_{2}$-antiplasmin, $\alpha_{2}$-macroglobulin, antithrombin III, or antileukoprotease could be demonstrated. $\alpha_{1}$-Antitrypsin and $\alpha_{1}$ antichymotrypsin could always be demonstrated immunochemically (Table 1). Especially the level of $\alpha_{1}$-antichymotrypsin was high. In fact, in colostrum from day 1 , it was higher than in normal serum. In relation to protein content, the $\alpha_{1}$-antichymotrypsin level was seven times and the $\alpha_{1}$-antitrypsin level two times higher during the first 3 days than those after 2 wk (Table 1).

The milk samples from the four mothers to preterm infants contained equal concentrations of $\alpha_{1}$-antitrypsin and $\alpha_{1}$-antichymotrypsin to those from mothers to fullterm infants.

Protease inhibiting activity. According to their protease inhibiting activity, the milk samples from 53 women from day 1,2 and 3 could be divided into two groups. In 35 samples a trypsin, chymotrypsin, and elastase inhibiting activity could be demonstrated in the $\alpha$-and $\beta$-region after electrophoresis, as shown in Figure 1. The most anodal migrating protease inhibiting band corresponds to the mobility of serum $\alpha_{1}$-antitrypsin. The weak chymotrypsin inhibiting band of slower mobility in the $\alpha_{1}$-region corresponds to serum $\alpha_{1}$-antichymotrypsin, whereas the broad zone of chymotrypsin inhibiting activity in the $\beta$-region has no correspondence to any inhibitor in human serum.
Protease inhibiting activity could not be detected in the 18 remaining samples (Fig. 1). Samples from day 4 or later always had a demonstrable protease inhibiting activity also from those mothers whose milk had no protease inhibiting activity on day $1-3$.

Immunocharacteristics of protease inhibitors. Crossed immunoelectrophoresis of human milk with antiserum against $\alpha_{1}$-antichymotrypin showed a uniform pattern in all specimens analysed. One minor component of $\alpha_{1}$-antichymotrypsin had the electrophoretic mobility of the inhibitor in normal human serum, whereas the major part of the $\alpha_{1}$-antichymotrypsin had a retarded electrophoretic mobility corresponding to the $\beta$-region (Fig. 2).

However, on analyses with crossed immunoelectrophoresis after the addition of increasing amounts of human pancreatic chymotrypsin, two different precipitate patterns were obtained. Those samples, that had no demonstrable protease inhibiting activity showed an unchanged precipitate pattern after the addition of chymotrypsin (Fig. 2B). On the contrary, milk specimens that had a protease inhibiting activity showed a change in the precipitate pattern with the addition of chymotrypsin. The $\alpha_{1}$-peak disappeared and the $\beta$-peak became slightly smaller and with a changed precipitate morphology indicating complexation (Fig. $2 \mathrm{C}$ and D).

Crossed immunoelectrophoresis of human milk with antiserum against $\alpha_{1}$-antitrypsin demonstrated mainly two different precipitate patterns. The milk specimens without protease inhibiting activity showed a major $\alpha_{1}$-antitrypsin fraction with slightly retarded electrophoretic mobility compared to $\alpha_{1}$-antitrypsin in normal serum and two minor peaks with $\alpha_{2}$ - and $\beta$-mobility (Fig. $3 A$ and $B$ ). This precipitate pattern was unchanged on addition of trypsin or chymotrypsin (Fig. $3 \mathrm{C}$ ). The remaining milk specimens showing protease inhibiting activity contained only one electrophoretic $\alpha_{1}$-antitrypsin component as demonstrated with crossed immunoelectrophoresis (Fig. 3D). The mobility of this component was identical with that of $\alpha_{1}$-antitrypsin in normal serum. This $\alpha_{1}$-antitrypsin component disappeared progressively on addition of human trypsin or chymotrypsin to the milk specimens before analyses with crossed immunoelectrophoresis (Fig. 3E). Simultaneously, a new $\alpha_{1}$-antitrypsin component appeared in the $\beta$-region indicating complexation.

Gel filtration analyses on Ultrogel Aca 44 were performed on two pools of milk each from 10 samples with and without protease inhibiting activity, respectively. The major part of immunoreactive $\alpha_{1}$-antitrypsin and $\alpha_{1}$-antichymotrypsin eluted in both cases in volumes corresponding to the molecular weight of about 50,000 and 70,000, respectively. After addition of human chymotrypsin in molar excess to the milk pool showing protease inhibiting activity, the pattern was changed. Immunoreactive $\alpha_{1}$-antitrypsin eluted corresponding to a molecular weight of about 70,000 and $\alpha_{1}$-antichymotrypsin corresponding to a molecular weight of about 90,000 , indicating complexation of both inhibitors. Addition of chymotrypsin to the milk without protease inhibiting activity however, did not produce any change in the elution pattern of the two inhibitors.

Protease activity of human milk. Protease (caseinolytic) activity was clearly demonstrated by radial digestion in the milk samples

Table 1. Protein, $\alpha_{1}$-antitrypsin $\left(\alpha_{1}-A T\right)$ and $\alpha_{1}$-antichymotrypsin $\left(\alpha_{1}-\right.$ Achy) [mean value $\pm S . E$. (n)] in human milk from various stages of lactation

\begin{tabular}{|c|c|c|c|c|c|c|c|}
\hline & Day 1 & Day 2 & Day 3 & Day 4 & Day 5 & Day 6-7 & $>14$ days \\
\hline Protein (g/liter) & $89 \pm 8.6(8)$ & $53 \pm 15(8)$ & $22 \pm 1.9(8)$ & & $20 \pm 0.8(8)$ & & $11 \pm 1.3(8)$ \\
\hline$\alpha_{1}-\mathrm{AT}(\%)^{1}$ & $16.1 \pm 1.5(21)$ & $8.3 \pm 1.1(35)$ & $4.2 \pm 0.6(42)$ & $3.1 \pm 0.2(36)$ & $2.7 \pm 0.2(28)$ & $1.9 \pm 0.2(13)$ & $1.0 \pm 0.3(11)$ \\
\hline$\alpha_{1}-\operatorname{Achy}(\%)^{1}$ & $133 \pm 11(21)$ & $75 \pm 13(34)$ & $33 \pm 5(40)$ & $26 \pm 2(36)$ & $22 \pm 4(26)$ & $19 \pm 4(14)$ & $2.4 \pm 0.5(8)$ \\
\hline $\begin{array}{l}\alpha_{1}-\mathrm{AT}(\mathrm{g} / \text { liter }) \\
\quad(100 \%=1.3 \mathrm{~g} / \text { liter })\end{array}$ & 0.21 & 0.11 & 0.055 & 0.04 & 0.035 & 0.025 & 0.013 \\
\hline $\begin{array}{l}\alpha_{1}-\text { Achy }(\mathrm{g} / \text { liter }) \\
\quad(100 \%=0.5 \mathrm{~g} / \text { /iter })\end{array}$ & 0.67 & 0.38 & 0.17 & 0.13 & 0.11 & 0.095 & 0.012 \\
\hline Ratio $\alpha_{1}-\mathrm{AT} /$ protein & 0.0024 & 0.0021 & 0.0025 & & 0.0018 & & 0.0012 \\
\hline Ratio $\alpha_{1}$-Achy/protein & 0.0075 & 0.0071 & 0.0077 & & 0.0055 & & 0.0011 \\
\hline
\end{tabular}

${ }^{1}$ Per cent of normal serum concentration. 

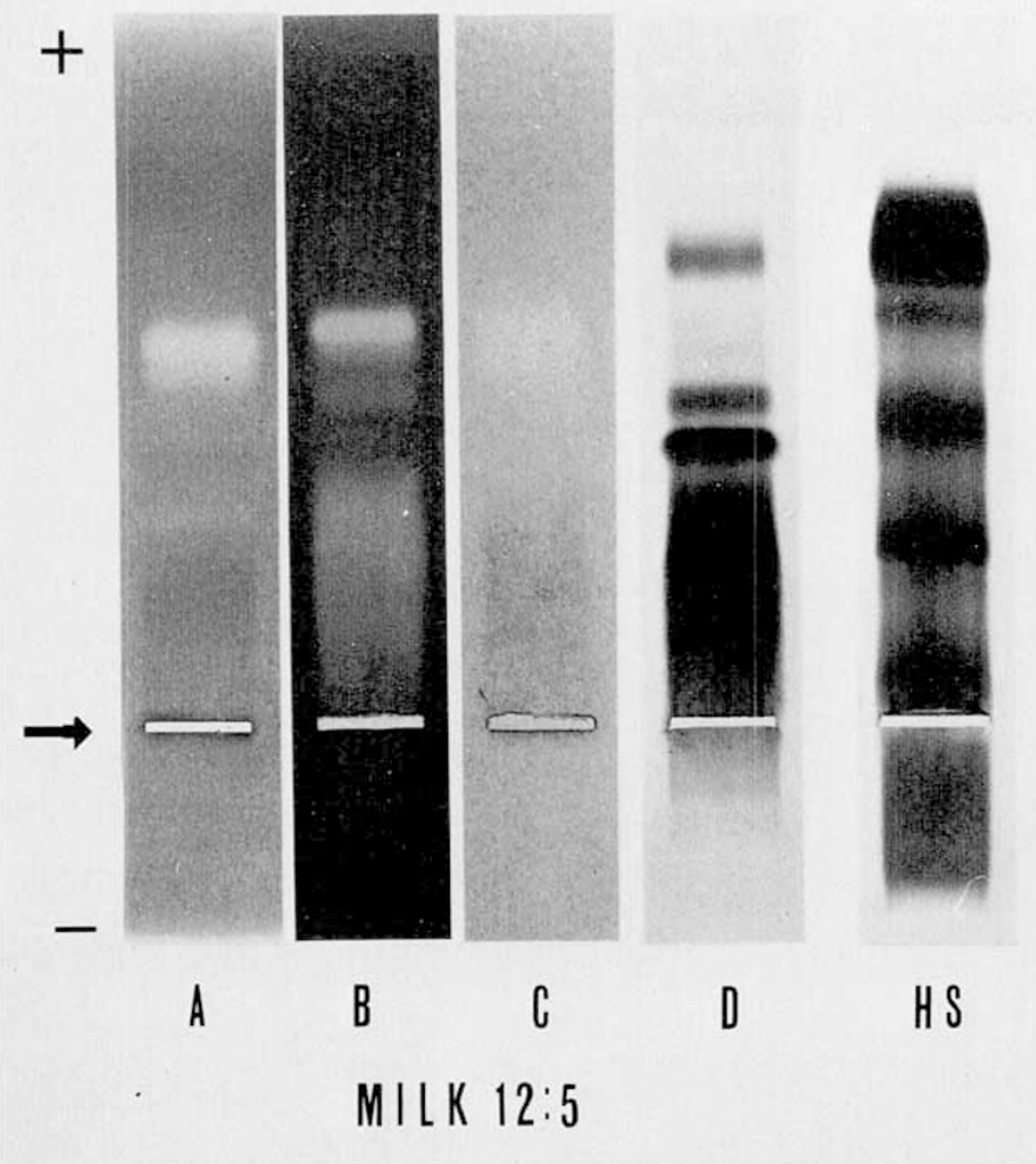
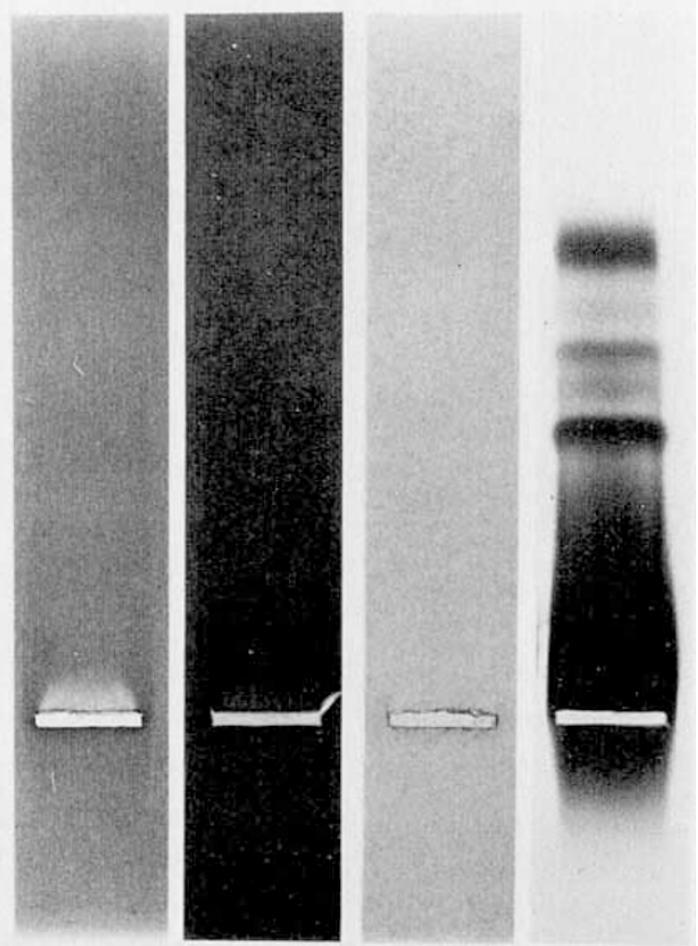

B

C

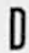

MIL K 14:1

Fig. 1. Agarose gel electrophoresis of human milk showing protease inhibiting activity (Milk 12:5) and no demonstrable protease inhibiting activity (Milk 14:1) stained for trypsin (A), chymotrypsin (B), and elastase inhibiting activity (C) or stained for protein with Commassie Briliant Blue (D). The protein stained electropherogram of human serum (HS) is shown for reference.

from days 1, 2, and 3, which had no demonstrable protease inhibiting activity. Elastinolytic activity could also be demonstrated in 16/18 samples. The 35 samples from days 1,2 , and 3 with a protease inhibiting activity had no, or low, caseinolytic activity. Samples from day 4 or later had no, or low caseinolytic and elastinolytic activity. Figure 4 shows that the caseinolytic activity in human milk was present in a broad region with a $\beta$ mobility in agarose gel electrophoresis. The esterolytic activity against CBZ-ANE had the same mobility (Fig. 4), whereas no activity could be detected against the substrate APNE. Esterolytic activity against the substrate CBZ-ANE was found in all milk samples throughout lactation.

\section{DISCUSSION}

This study shows that the main protease inhibitors in human milk are $\alpha_{1}$-antichymotrypsin and $\alpha_{1}$-antitrypsin. Other known protease inhibitors, e.g., $\alpha_{2}$-macroglobulin, inter $\alpha$-trypsin inhibitor, $\alpha_{2}$-antiplasmin, antithrombin III, and antileukoprotease, were found in only trace amounts. No specific secretory inhibitors were detected as found in colostrum of other species, e.g., pig and cow (24).

We emphasize the large concentration of $\alpha_{1}$-antichymotrypsin in relation to that of $\alpha_{1}$-antitrypsin in colostral milk. In fact, its concentration is about 8 times larger than could be expected. This suggests that the large amounts of $\alpha_{l}$-antichymotrypsin in colostrum may be the result of a local production or accumulation in the mammary gland in this early stage of lactation rather than an expression of the big protein content per se. A similarly high relative concentration of $\alpha_{1}$-antichymotrypsin has not been ob- served in other fluids in man, with the possible exception of seminal plasma (21).

Protease inhibiting activity was demonstrable in about twothirds of the samples from day 1-3 and in all samples from later stages of lactation. These milk samples possessed low or undetectable proteolytic (caseinolytic) activity. As judged from results of analyses with crossed immunoelectrophoreses and gelfiltration, $\alpha_{1}$-antitrypsin and $\alpha_{1}$-antichymotrypsin were able to form complexes with trypsin or chymotrypsin added to the samples.

The remaining third of the colostrum samples showed no demonstrable protease inhibiting activity in spite of the presence of immunoreactive protease inhibitors. These samples showed an evident caseinolytic activity. $\alpha_{1}$-Antitrypsin was present as three electrophoretic fractions. The major component showed a somewhat slower electrophoretic mobility in the $\alpha_{1}$-region than found normally. The results of the gel filtration analyses indicated that this fraction had a molecular size roughly corresponding to that of native $\alpha_{1}$-antitrypsin. This seems to exclude complexation. Similar nonfunctioning $\alpha_{1}$-antitrypsin fractions have been found earlier in other biologic materials such as bronchial lavage fluid (22) and uterine secretions (2). They may represent $\alpha_{1}$-antitrypsin inactivated by oxidative or other processes (9), or the inhibitor is a part of a cleaved enzyme inhibitor complex (1). The relatively small $\alpha_{1}$-antitrypsin fractions with electrophoretic $\alpha_{2}$ - and $\beta$-mobility might represent $\alpha_{1}$-antitrypsin complexed by granulocyte proteases (13).

$\alpha_{1}$-Antichymotrypsin showed a precipitate pattern different from that in normal serum on crossed immunoelectrophoresis with the major fraction showing $\beta$-mobility indicating that this fraction may represent a complex with a protease (18). But the same 


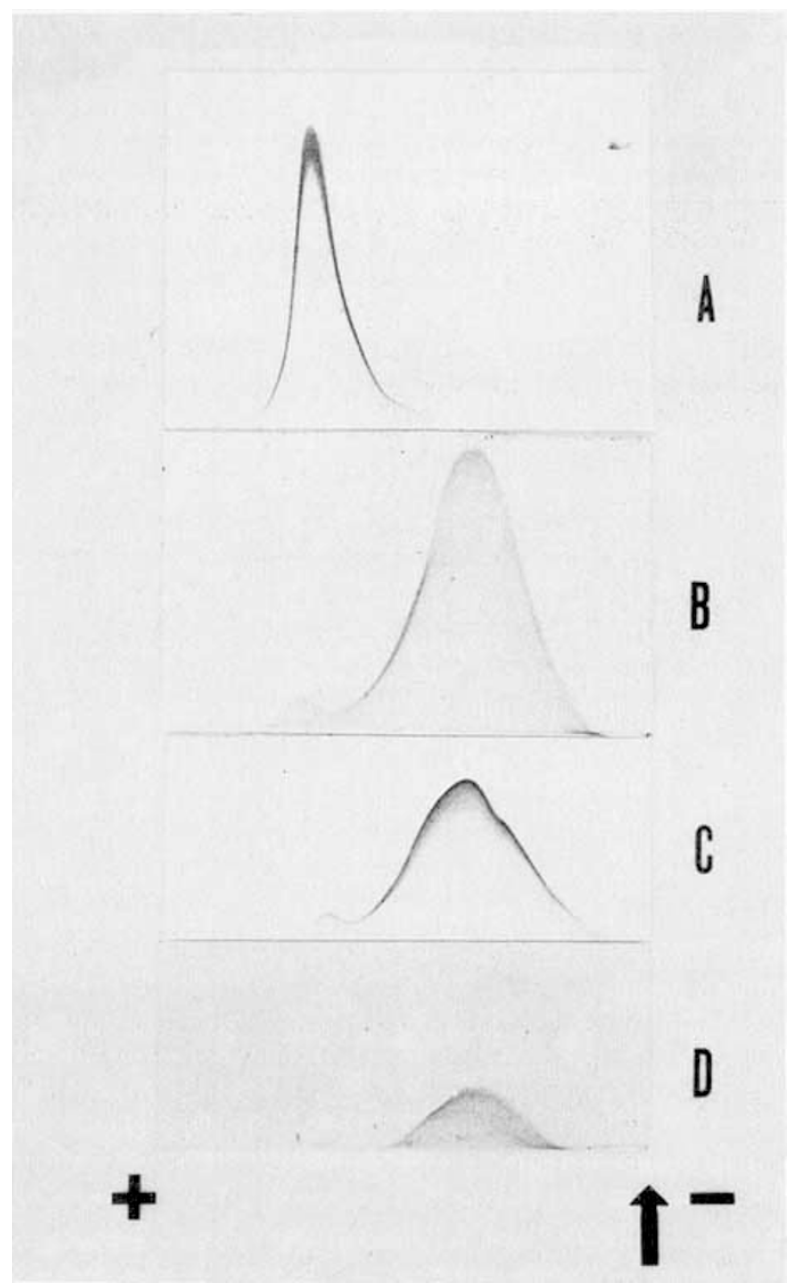

Fig. 2. Precipitate patterns obtained on crossed immunoelectrophoresis with human $\alpha_{1}$-antichymotrypsin of human serum (A), human milk without protease inhibiting activity (B), (the same pattern was obtained also after the addition of human chymotrypsin in molar excess), human milk with protease inhibiting activity before (C) and after (D) the addition of human chymotrypsin in molar excess.

pattern of $\alpha_{1}$-antichymotrypsin was found in milk both with and without chymotrypsin inhibiting activity. From the crossed immunoelectrophoretic analyses and also from the protease inhibitor stainings of agarose gels, it was evident that the $\beta$-component of $\alpha_{1}$-antichymotrypsin could both have and not have chymotrypsin inhibiting activity. A similar electrophoretic pattern of $\alpha_{1}$-antichymotrypsin has been recently demonstrated in seminal plasma $(\mathrm{H}$. Weiber, personal communication). It might perhaps be the result of limited proteolysis which under some conditions leads to inactivation of the inhibitor and in others only to a changed electrophoretic mobility. The changed electrophoretic pattern of $\alpha_{1}$-antichymotrypsin might also be a result of the transfer of the inhibitor from serum over the secretory epithelium into the milk.

The physiologic function of the protease inhibitors in human milk might both be exerted in the mammary gland and in the infant, preferentially in the gastrointestinal tract. Probably the protease inhibitors protect the mammary gland from local proteolytic activity during colostrum formation. However, one-third of the colostrum samples showed no protease inhibiting activity but instead proteolytic activity, concomitant with the presence of inactivated protease inhibitors, indicating a consumption of the inhibitors in these samples. The consumption may be the result both of complex formation with proteases and inactivation caused by limited proteolysis. The clinical significance of the different protease inhibiting patterns and the presence of proteolytic activity in colostrum from various mothers was followed up in 17 mothers from each group. This inquiry did not display any particular differences concerning any feeding problems; in the mothers as mastitis, and in the infants as nutritional problems, infantile colic or increased susceptibility to infections.

The nature of the proteolytic activity in human milk is unknown $(5,20)$. We found proteolytic (caseinolytic) activity preferentially

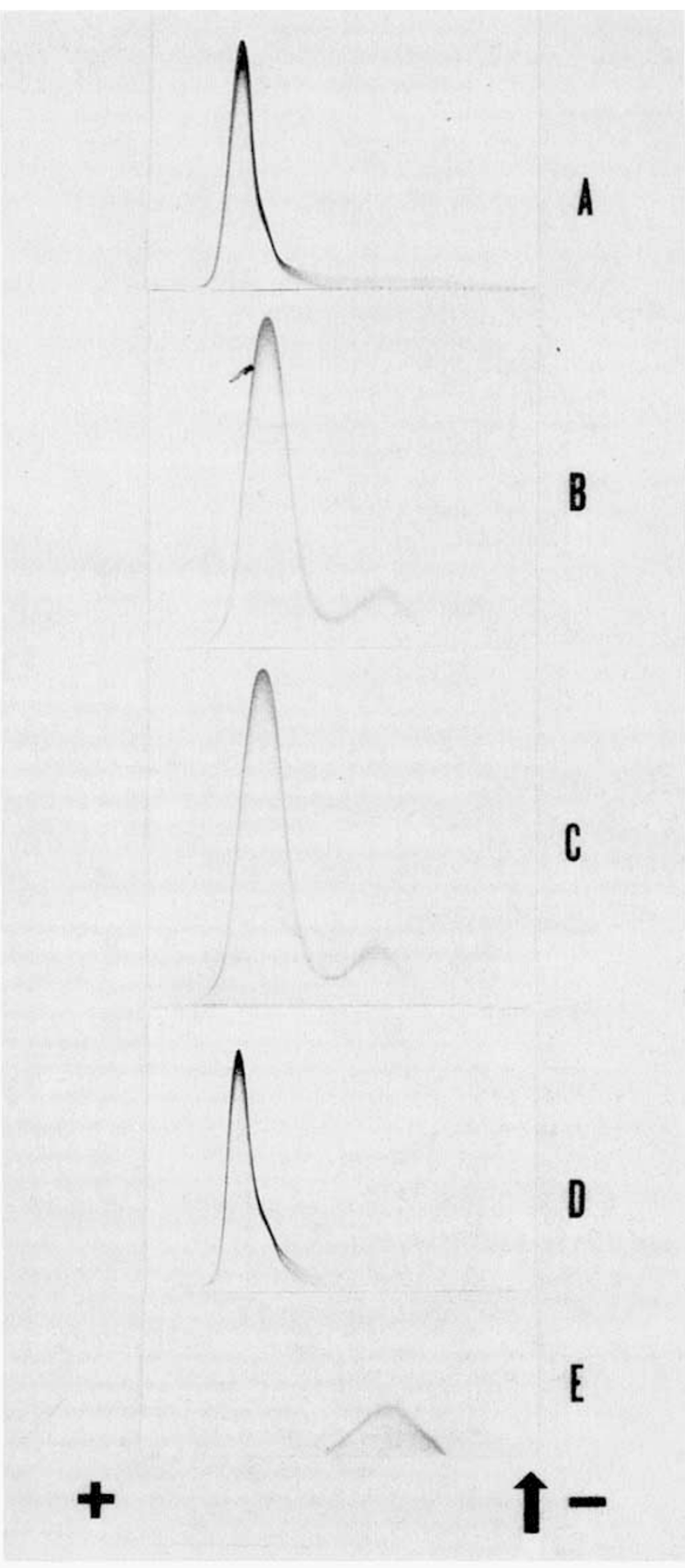

Fig. 3. Precipitate patterns obtained on crossed immunoelectrophoresis with antiserum against human $\alpha_{1}$-antitrypsin of human serum (A), human milk without protease inhibiting activity before (B) and after (C) the addition of human trypsin in molar excess. (D) and (E) show the results of the corresponding analysis of human milk with protease inhibiting activity, before (D) and after (E) the addition of human trypsin in molar excess. 


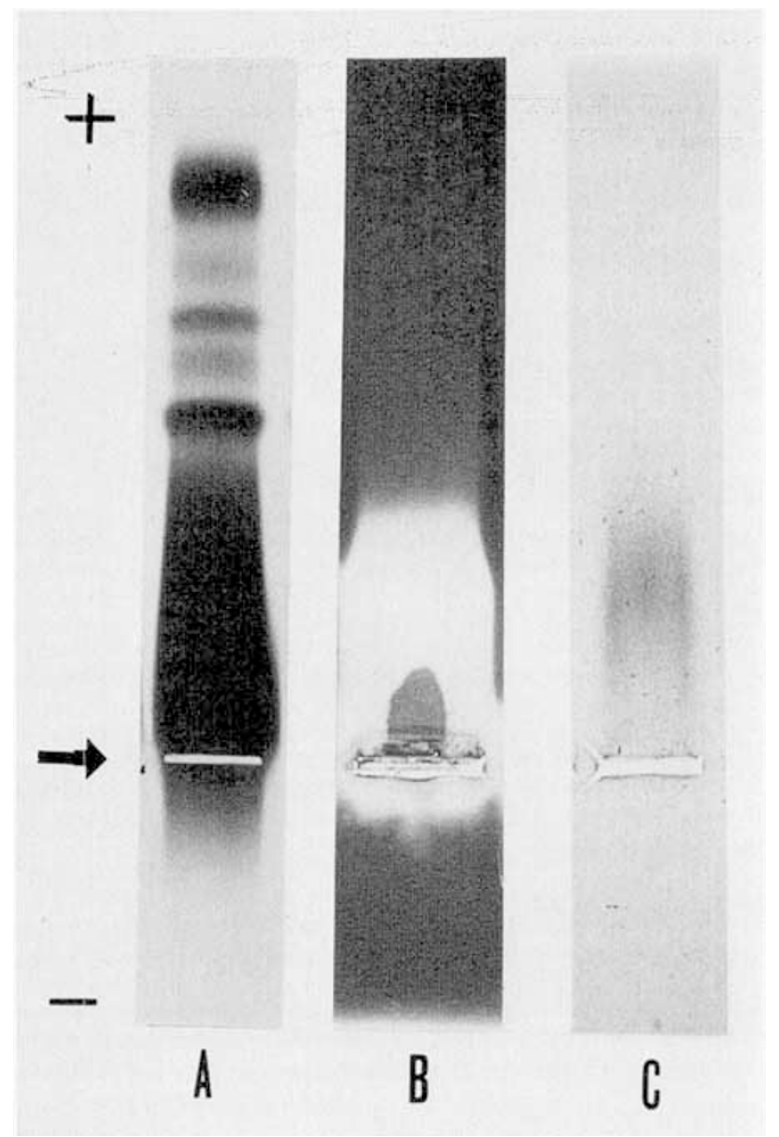

Fig. 4. Agarose gel electrophoresis of human milk from the first day after delivery stained for protein with Commassie Brilliant Blue R-250 (A), processed to show the proteolytic activity, i.e., caseinolytic activity in casein-agarose (B), and esterolytic activity after incubation with $C B Z$ ANE (C).

in colostrum. The caseinolytic activity had an electrophoretic mobility to the $\beta$-region. Moreover, human milk showed an activity in the same electrophoretic region against the low molecular weight substrate, CBZ-ANE, which is commonly used to analyse elastase-like enzymes. No activity was found against the trypsin-, chymotrypsin-substrate APNE. It might be possible that leukocytes are one source of the elastase-like enzyme in human milk. In cow's milk the proteolytic activity has been shown to have similarities to blood plasmin and to be associated to the casein fraction $(3,6)$. Further studies are in progress to elucidate the nature of the proteases in human milk.

In conclusion, the protease inhibiting activity in human milk can be accounted for by $\alpha_{1}$-antitrypsin and $\alpha_{1}$-antichymotrypsin, whereas other protease inhibitors are present in trace amounts only. A remarkably high $\alpha_{1}$-antichymotrypsin concentration in early colostrum suggests a local production of this inhibitor. A disparity between the protease inhibiting activity and the immunologically determined concentration of the two main inhibitors is found in about $1 / 3$ of the day $1-3$ colostrum samples. This is explained by the presence of nonreactive protease inhibitor mol- ecules and, in addition, protease-antiprotease complexes. So far no clinically adverse effect of this protease-antiprotease imbalance has been demonstrated in mother or infant.

\section{REFERENCES AND NOTES}

1. Balldin, G., Laurell, C. B., and Ohlsson, K.: Increased catabolism of $\alpha$-macroglobulins after intravenous infusion of trypsin- $\alpha_{1}$-antitrypsin complexes in dogs. Hoppe-Seyler's Z. Physiol. Chem.. 359: 699 (1978).

2. Casslén. B. and Ohlsson. K.: $\alpha_{1}$-antitrypsin-complexation and inactivation in the uterine fluid of UID-users. Acta Obstet. Gynecol. Scand., 60: 103 (1981).

3. Eigel. W. N., Hofman, C. J.. Chibber, B. A. K.. Tomich, J. M., Keenan, T. W., and Mertz. E. T.: Plasmin-mediated proteolysis of casein in bovine milk. Proc. Natl. Acad. Sci. USA, 76: 2244 (1979).

4. Ganrot. P. O.: Crossed immunoelectrophoresis. Scand. J. Clin. Lab. Invest., 29: (Suppl. 124) 39 (1972).

5. Heyndrickz. G. V.: Further investigations of the enzymes in human milk. Pediatrics, 31: 1019 (1963).

6. Humbert, G. and Alais. C.: The milk proteinase system. J. Dairy Res., 46: 559 (1979).

7. Hyanek von J., Noskova, R., and Cafour Kova, Z.: Die Trypsin-Inhibitoraktivität der Muttermilch in der ersten Woche nach der Entbindung. Ann. Paediatr. 204: 125 (1965).

8. Johansson. B. G.: Agarose gel electrophoresis. Scand. J. Clin. Lab. Invest., 29 (Suppl. 124) 7 (1972).

9. Johnson, D. and Tuvis, J.: The oxidative inactivation of human $\alpha_{1}$-proteinase inhibitor. Further evidence for methionine at the reactive center. J. Biol. Chem., 254: 4022 (1971).

10. Laurell, C. B.: Electroimmunoassay. Scand. J. Clin. Lab. Invest., 29 (Suppl. 124) 21 (1972).

11. Lindberg. T.: Protease inhibitors in human milk. Pediatr. Res., 13: 969 (1979).

12. Lowry, O. H., Rosebrough, N. J., Farr. A. L., and Randall, R. J.: Protein measurement with the Folin phenol reagent. J. Biol. Chem., 19.3: 265 (1959).

13. Ohlsson, K.: Neutral leukocyte proteases and elastase inhibited by plasma $\alpha_{1}$ antitrypsin. Scand. J. Clin. Lab. Invest., 28: 25 I (1971).

14. Ohlsson. K.: Interactions between granulocyte proteases and protease inhibitors in the lung. Bull. Europ. Physiopath. Resp. I6 (Suppl.): 209 (1980).

15. Ohlsson, K. and Olsson. I.: The neutral proteases of human granulocytes. Isolation and partial charachterization of granulocyte elastase. Eur. J. Biochem., 42: 519 (1974).

16. Ohlsson, K. and Skude, G.: Demonstration and semiquantitative determination of complexes between various proteases and human $\alpha_{2}$-macroglobulin. Clin. Chim. Acta, 60: 1 (1976).

17. Ohlsson, K.. Tegner. H.. and Åkesson. U.: Isolation and partial characterization of a low molecular weight acid-stable protease inhibitor from human bronchial secretion. Hoppe-Seyler`s Z. Physiol. Chem.. 358: 583 (1977).

18. Ohlsson. K. and Åkesson, U.: $\alpha_{1}$-Antichymotrypsin interaction with cationic proteins from granulocytes. Clin. Chim. Acta., 73: 285 (1976).

19. Ouchterlony. Ö.: In vitro method for testing the toxin-producing capacity of diphteria bacteria. Acta Pathol. Microbiol. Scand., 25: 186 (1948).

20. Storrs. A. B. and Hull. M. E.: Proteolytic enzymes in human and cow's milk. J. Dairy Sci., 39: 1097 (1956)

21. Tauber, P. F. and Zaneveld. L. J. D.: Human semen and fertility regulation in men. In: Hafoez, Ed., p. 159. (C. V. Mosshy, St. Louis, MO 1976).

22. Tegner, H.: Quantitation of human granulocyte protease inhibitors in nonpurulent bronchial lavage fluid. Acta Otolaryngol. Stockh, 85: 282 (1978).

23. Weström. B. and Carlsson. L.: Trypsin inhibitors in serum of adult and suckling rats and in rat milk. Int. J. Biochem., 7: 41 (1976).

24. Weström. B.. Carlsson, L., and Karlsson. B.: The importance of colostral trypsin inhibitors for the absorption of proteins by the neonatal piglet. In: W. A Hemmings. Ed.. Protein transmission through living membranes pp 225-232 (Elsevier/North-Holland Biomedical Press 1979).

25. Requests for reprints should be addressed to: Tor Lindberg. M.D. Department of Pediatrics. Malmö General Hospital, S-214 01 Malmö. Sweden.

26. Mrs. Birgitta Benediktsson. Miss Britta Nilsson, Mrs. Marie-Louise Nilsson gave skilful technical assistance.

27. This work was supported by grants from the Dir. A. Påhlsson Foundation, the M. Bergwall Foundation. the Swedish Baby Food Industry Fund for Nutritional Research, the Swedish Nutrition Foundation, the Swedish Natural Science Research Council, the Swedish Medical Research Council 103910. B $82-17 X-0310-10 A)$, the Foundation of Thorsten and Elsa Segerfalk and The Medical Faculty. University of Lund. Sweden.

28. Received for publication July 6, 1981

29. Accepted for publication December 2. 1981. 